\title{
Innovación docente en la información política en asuntos europeos
}

\section{Educational innovation in political journalism covering European affairs}

RUBÉN RIVAS-DE-ROCA

ORCID: https://orcid.org/0000-0001-5842-4533

Universidad de Sevilla

Departamento de Periodismo II

rrivasderoca@us.es

DOI: http://dx.doi.org/10.12795/9788447231003.058

Pp.: 1229-1250 


\section{Contexto de la asignatura}

El Ciclo de Mejora en el Aula (en adelante, CIMA) se ha implementado en la asignatura Periodismo Político y Económico, perteneciente al primer cuatrimestre del tercer curso del Grado en Periodismo, que se imparte en la Facultad de Comunicación de la Universidad de Sevilla. Se trata de una materia obligatoria que consta de 6 créditos ECTS, convertidos en 60 horas de clase teórico-prácticas. La docencia se articula en cuatro horas semanales, en forma de dos sesiones de dos horas (miércoles y jueves). Entre los cuatro grupos del Grado en Periodismo hay más de 250 alumnos matriculados. El CIMA solo se ha implantado en el Grupo 1 (75 estudiantes), del cual soy el único profesor responsable en el curso 2020-2021.

\section{Diseño previo del CIMA}

\section{Mapa de contenidos y problemas}

El contenido estructurante de este CIMA pasa por la importancia vehicular de la especialización periodística en asuntos europeos, derivada de sus implicaciones democráticas, al constituir un objeto informativo de gran impacto en la vida ciudadana que no dispone de una cobertura acorde, ni cuantitativa ni cualitativamente (Fajardo-Trigueros y Rivas-de-Roca, 2020). Este contenido primigenio lleva a profundizar en los rasgos de la especialización, singularmente en lo relativo a la despolitización. La complejidad burocrática del tema provoca además que se deban concebir fórmulas atractivas de afrontarlo.

A partir de la pregunta general ¿A quién llamo para hablar con Europa?, atribuida a Henry Kissinger, se formulan tres grandes problemas para el CIMA 2. Estos problemas se trabajan al mismo tiempo, siguiendo un único modelo metodológico:

Ciclos de Mejora en el Aula (2020). Experiencias de Innovación Docente de la US Esta obra se distribuye con la licencia Creative Commons 
- Problema 1. ¿Por qué la información política en asuntos europeos es de impacto?

- Problema 2. ¿Qué implicaciones democráticas tiene informar de esa manera?

- Problema 3. ¿Cómo se puede hacer más atractivo este tipo de periodismo?

Leyenda del mapa de contenidos:

- Color negro: contenidos actitudinales (CA) o valores. Estructurante en mayúsculas.

- Color azul: contenidos procedimentales intelectuales (CPI).

- Color blanco: contenidos conceptuales (CC).

- Color verde agua: contenidos referentes a datos (CD).

- Color amarillo: contenidos procedimentales psicomotrices (CPP)

- Híbrido amarillo entre blanco: contenidos procedimentales (tanto intelectuales como psicomotrices).

Ciclos de Mejora en el Aula (2020). Experiencias de Innovación Docente de la US Esta obra se distribuye con la licencia Creative Commons 


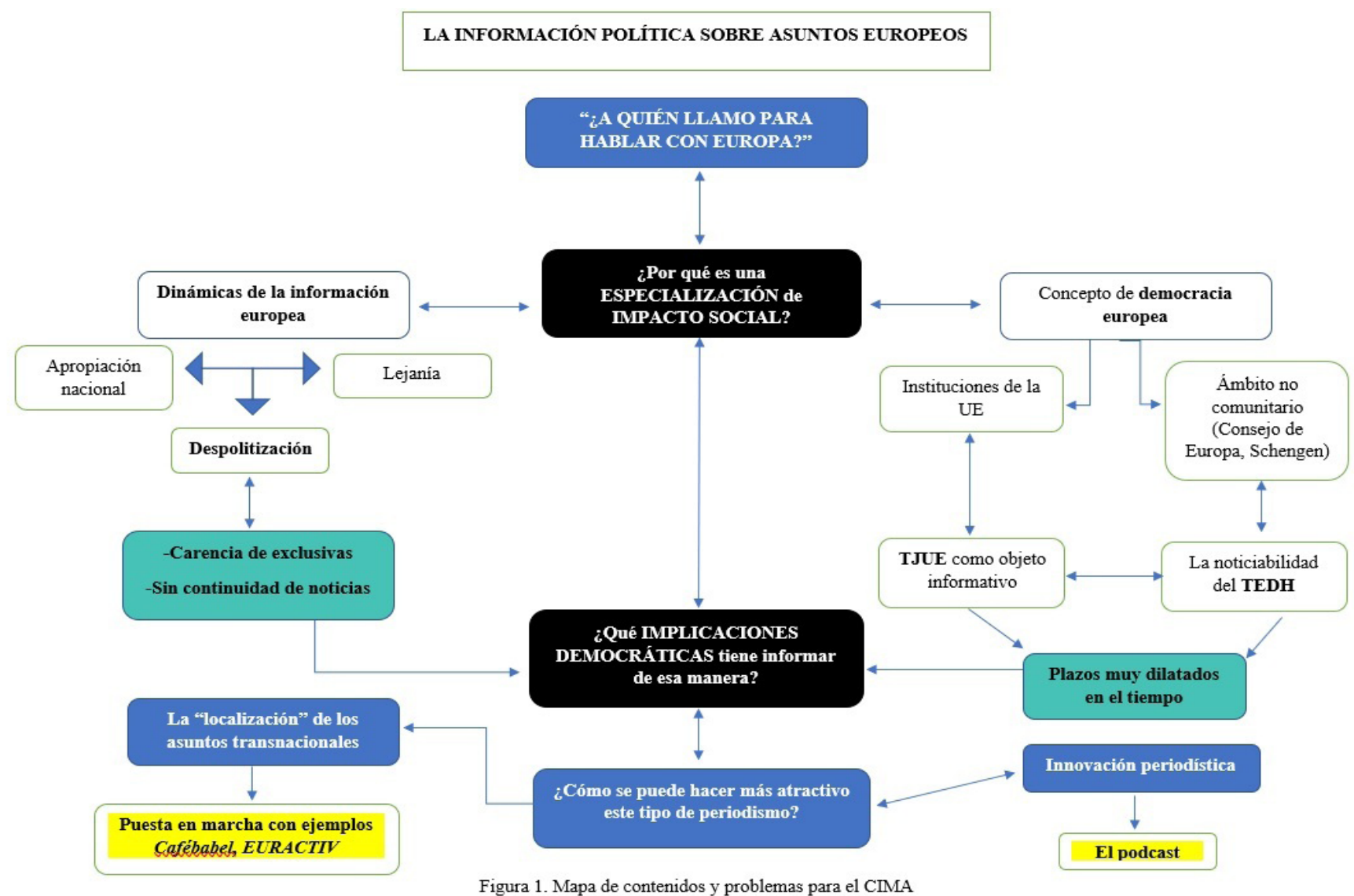

Ciclos de Mejora en el Aula (2020). Experiencias de Innovación Docente de la US cC (7) $\ominus$ Esta obra se distribuye con la licencia Creative Commons cc) (†) $\Theta$ Reconocimiento-NoComercial-SinObraDerivada Internacional (CC BY-NC-ND 4.0.) 


\section{Modelo metodológico posible y secuencia de actividades programadas}

El área de información política es transversal al resto de especializaciones periodísticas, puesto que funciona como marco estructural en el que se desarrollan el resto de actividades en una sociedad democrática. Por ello, he diseñado un Modelo Metodológico Posible que presenta y contrasta la abundante teoría en la materia con las ideas recabadas por los estudiantes, a través de estudios de casos con implicaciones éticas. Apuesto por focalizar el CIMA en la información política sobre asuntos europeos, tradicionalmente ignorada, con el fin de lograr un modelo en el que los alumnos participen en el conocimiento acerca de un tema que probablemente desconocían.

Los casos prácticos funcionan como dilemas éticos, para los que proporciono una serie de preguntas que deben abordar en grupo tras la visualización de varios documentos. Dichos equipos de trabajo se articulan como pequeñas redacciones estables de alumnos, que se encargan de la sección de un medio televisivo dedicado a política europea. Las cuestiones me permiten orientar la discusión hacia los contenidos principales del temario (dinámicas de la información europea y concepto de democracia comunitaria), de tal forma que a continuación se confrontan las impresiones del estudiantado con las aportaciones teóricas al respecto.

Por su parte, la asignatura tiene una carga práctica de análisis de textos, por lo que he elegido una pieza que se ajusta al tema tratado y a la que he añadido preguntas en torno a cuestiones éticas. Estos documentos se trabajan en grupo, como marca el programa. No obstante, en varias sesiones del Curso General de Docencia Universitaria (CGDU) los comentarios de los compañeros me hicieron darme cuenta de la necesidad de espolear el trabajo

Ciclos de Mejora en el Aula (2020). Experiencias de Innovación Docente de la US Esta obra se distribuye con la licencia Creative Commons 
individual, así que decidí que el trabajo semanal entre sesiones fuera elaborado de esa manera. La tarea consiste en ver y sintetizar un reportaje audiovisual.

El modelo propuesto es factible, dado que modifica la dinámica de la asignatura hacia un rol más participativo de los alumnos, si bien mantiene ciertos contenidos centrales. Un primer experimento de cuatro horas mostró que estas prácticas aumentaban la participación, evidenciando además la necesidad de controlar el tiempo e intentar mantener un alto grado de interés durante todas las sesiones. Por ello, los tipos de casos prácticos diversifican los medios elegidos para que no todos aludan a la prensa. Esto pretende ayudar asimismo a la elaboración de un podcast donde apliquen lo aprendido.

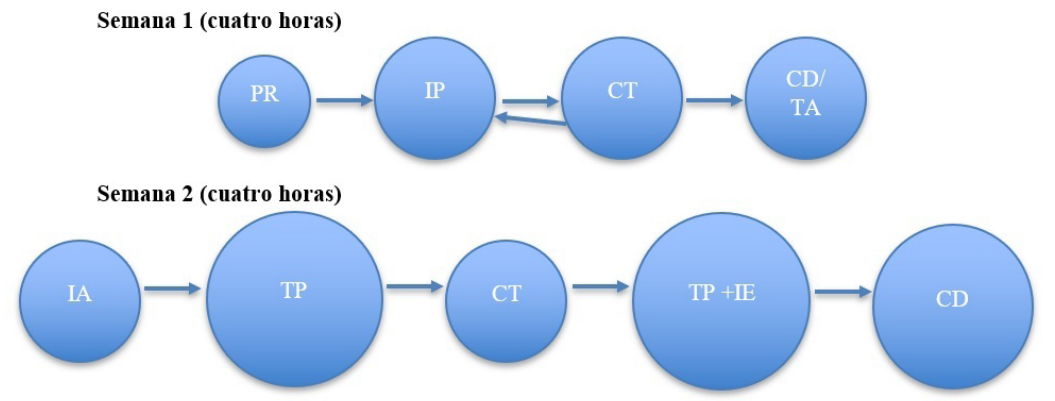

Figura 2. Modelo metodológico posible para el CIMA

La leyenda de siglas del modelo metodológico posible es la siguiente: PR (problema), IP (ideas previas), CT (contraste teoría), CD (conclusiones y debate), TA (tarea), IA (ideas alumnos), TP (trabajo práctico), IE (informe ético).

A continuación, se muestra la secuencia detallada de actividades en orden cronológico, generando una tabla para cada una de las semanas de aplicación del CIMA. Con estas actividades se pretende poner en práctica el modelo metodológico posible (De-Alba y Porlán, 2017), de manera coherente para que los estudiantes trabajen sobre los problemas y contenidos.

Ciclos de Mejora en el Aula (2020). Experiencias de Innovación Docente de la US Esta obra se distribuye con la licencia Creative Commons 
Tabla 1. Secuencia detallada de actividades del CIMA para la semana 1

\begin{tabular}{|l|c|l|c|}
\hline \multicolumn{3}{|c|}{ SEMANA 1. ¿Por qué la información política en asuntos europeos es una } \\
especialización de impacto?
\end{tabular}

Ciclos de Mejora en el Aula (2020). Experiencias de Innovación Docente de la US Esta obra se distribuye con la licencia Creative Commons Reconocimiento-NoComercial-SinObraDerivada Internacional (CC BY-NC-ND 4.0.) 


\begin{tabular}{|c|c|c|c|}
\hline $\begin{array}{l}\text { 5. Confrontación } \\
\text { características } \\
\text { información europea } \\
\text { Recursos: } 3 \\
\text { diapositivas }\end{array}$ & CT & $\begin{array}{l}\text { Retomo las respuestas de los } \\
\text { estudiantes para enmarcarlas } \\
\text { en dos grandes rasgos de la } \\
\text { información europea (carencia de } \\
\text { exclusivas y falta de continuidad } \\
\text { en las noticias). }\end{array}$ & $\begin{array}{c}20 \\
\text { minutos }\end{array}$ \\
\hline $\begin{array}{l}\text { 6. Vídeo introducción } \\
\text { funcionamiento UE } \\
\text { Recursos: enlace de } \\
\text { vídeo. }\end{array}$ & CT & $\begin{array}{l}\text { Proyección de un vídeo } \\
\text { introductorio ("The European } \\
\text { Union explained"), que anticipa el } \\
\text { concepto de democracia europea } \\
\text { sobre el que opera el tipo de } \\
\text { periodismo estudiado. }\end{array}$ & $\begin{array}{c}10 \\
\text { minutos }\end{array}$ \\
\hline $\begin{array}{l}\text { 7. Las elecciones al } \\
\text { Parlamento Europeo } \\
\text { Recursos: noticias } \\
\text { digitalizadas, guion } \\
\text { de preguntas. }\end{array}$ & IP & $\begin{array}{l}\text { Se exponen textos de El País y } \\
\text { La Vanguardia que revelan un } \\
\text { tratamiento de las elecciones } \\
\text { europeas vinculado a cuestiones } \\
\text { anecdóticas. Se formulan } \\
\text { preguntas para discutir en grupo. }\end{array}$ & $\begin{array}{c}30 \\
\text { minutos }\end{array}$ \\
\hline $\begin{array}{l}\text { 8. Confrontación } \\
\text { instituciones (no) } \\
\text { comunitarias } \\
\text { Recursos: } 5 \\
\text { diapositivas }\end{array}$ & CT & $\begin{array}{l}\text { Explicación de la diferencia } \\
\text { entre las instituciones de la UE y } \\
\text { políticas europeas que implican a } \\
\text { más países, o que están al margen } \\
\text { de ella (Consejo de Europa). }\end{array}$ & $\begin{array}{c}25 \\
\text { minutos }\end{array}$ \\
\hline $\begin{array}{l}\text { 9. Sintesis semana } 1 \\
\text { Recursos: pizarra } \\
\text { para anotar las ideas. }\end{array}$ & $C D$ & $\begin{array}{l}\text { Puesta en común de lo trabajado } \\
\text { durante las clases. Cada grupo } \\
\text { debe poner por escrito y contar } \\
\text { sus principales conclusiones de la } \\
\text { primera semana del CIMA. }\end{array}$ & $\begin{array}{c}15 \\
\text { minutos }\end{array}$ \\
\hline $\begin{array}{l}\text { 10. Tarea entre } \\
\text { sesiones } \\
\text { Recursos: diapositiva } \\
\text { que expone la tarea. }\end{array}$ & $\begin{array}{c}\mathrm{CD} / \\
\mathrm{TA}\end{array}$ & $\begin{array}{l}\text { Se propone y explica una tarea } \\
\text { para la clase siguiente, basada en } \\
\text { analizar un reportaje audiovisual } \\
\text { del programa "Europa } 2020 \text { ". }\end{array}$ & $\begin{array}{c}5 \\
\text { minutos }\end{array}$ \\
\hline
\end{tabular}

Ciclos de Mejora en el Aula (2020). Experiencias de Innovación Docente de la US Esta obra se distribuye con la licencia Creative Commons Reconocimiento-NoComercial-SinObraDerivada Internacional (CC BY-NC-ND 4.0.) 
Tabla 2. Secuencia detallada de actividades del CIMA para la semana 2

\begin{tabular}{|c|c|c|c|}
\hline Actividad & Fase & Descripción & Tiempo \\
\hline $\begin{array}{l}\text { 11. Ideas anteriores } \\
\text { Recursos: encuesta } \\
\text { corta con Wooclap. }\end{array}$ & IA & $\begin{array}{l}\text { Realización de una encuesta } \\
\text { corta mediante Wooclap } \\
\text { para reflejar las ideas que } \\
\text { los estudiantes traen de la } \\
\text { semana anterior. Dos bloques } \\
\text { sobre manejo de conceptos } \\
\text { y valoraciones de prácticas } \\
\text { profesionales. }\end{array}$ & $\begin{array}{c}15 \\
\text { minutos }\end{array}$ \\
\hline $\begin{array}{l}\text { 12. Trabajo práctico } \\
\text { sobre texto } \\
\text { periodístico } \\
\text { Recursos: material } \\
\text { disponible en EV. }\end{array}$ & TP & $\begin{array}{l}\text { Análisis grupal de un reportaje } \\
\text { periodistico que desarrolla una } \\
\text { buena práctica, dirigida a dos } \\
\text { sujetos jurídicos europeos (TJUE } \\
\text { y TEDH) que los informadores } \\
\text { suelen confundir. }\end{array}$ & $\begin{array}{c}40 \\
\text { minutos }\end{array}$ \\
\hline $\begin{array}{l}\text { 13. Debate colectivo } \\
\text { del documento } \\
\text { periodístico } \\
\text { Recursos: } \\
\text { pizarra para las } \\
\text { conclusiones. }\end{array}$ & TP & $\begin{array}{l}\text { Puesta en común de los } \\
\text { informes grupales. Se debate } \\
\text { acerca de las conclusiones y se } \\
\text { resuelven posibles dudas. }\end{array}$ & $\begin{array}{c}15 \\
\text { minutos }\end{array}$ \\
\hline $\begin{array}{l}\text { 14. Confrontación } \\
\text { "localización" e } \\
\text { innovación } \\
\text { Recursos: } 4 \\
\text { diapositivas } \\
\end{array}$ & CT & $\begin{array}{l}\text { Alusión a las principales } \\
\text { aportaciones académicas } \\
\text { referentes a innovación y } \\
\text { "localización" de los asuntos } \\
\text { políticos. }\end{array}$ & $\begin{array}{c}20 \\
\text { minutos }\end{array}$ \\
\hline $\begin{array}{l}\text { 15. Programa } \\
\text { radiofónico } \\
\text { ilustrativo de } \\
\text { "localización" } \\
\text { Recursos: enlace al } \\
\text { material sonoro. }\end{array}$ & CT & $\begin{array}{l}\text { Escucha activa del programa } \\
\text { "EuropeandUS", de Radius, } \\
\text { que muestra cómo hacer de } \\
\text { interés temas europeos al } \\
\text { enfocarlos desde una óptica de } \\
\text { proximidad. }\end{array}$ & $\begin{array}{c}10 \\
\text { minutos }\end{array}$ \\
\hline
\end{tabular}

Ciclos de Mejora en el Aula (2020). Experiencias de Innovación Docente de la US Esta obra se distribuye con la licencia Creative Commons Reconocimiento-NoComercial-SinObraDerivada Internacional (CC BY-NC-ND 4.0.) 


\begin{tabular}{|c|c|c|c|}
\hline $\begin{array}{l}\text { 16. Elaboración de } \\
\text { una propuesta de } \\
\text { podcast } \\
\text { Recursos: vídeo } \\
\text { introductorio al } \\
\text { podcast. }\end{array}$ & TP & $\begin{array}{l}\text { Elaboración en los grupos } \\
\text { definidos de un borrador de } \\
\text { guion para un podcast (de } 10 \\
\text { minutos de duración) sobre } \\
\text { una noticia de política europea } \\
\text { a su elección. }\end{array}$ & $\begin{array}{c}40 \\
\text { minutos }\end{array}$ \\
\hline $\begin{array}{l}\text { 17. Redacción de las } \\
\text { implicaciones éticas }\end{array}$ & CT & $\begin{array}{l}\text { Redacción individual de un } \\
\text { informe deontológico sobre las } \\
\text { implicaciones éticas que posee } \\
\text { lo visto durante esas cuatro } \\
\text { clases en su futuro profesional. }\end{array}$ & $\begin{array}{c}30 \\
\text { minutos }\end{array}$ \\
\hline $\begin{array}{l}\text { 18. Conclusiones } \\
\text { finales y cierre } \\
\text { Recursos: } 2 \\
\text { diapositivas, } \\
\text { que aluden a los } \\
\text { problemas y las } \\
\text { tareas formuladas. }\end{array}$ & $\begin{array}{c}\mathrm{CD} / \\
\mathrm{TA}\end{array}$ & $\begin{array}{l}\text { A modo de conclusiones } \\
\text { recuerdo los tres grandes } \\
\text { problemas afrontados y las } \\
\text { respuestas dadas por los } \\
\text { estudiantes. Se abre un turno } \\
\text { para comentarios. }\end{array}$ & $\begin{array}{c}20 \\
\text { minutos }\end{array}$ \\
\hline $\begin{array}{l}\text { 19. Cuestionario final } \\
\text { Recursos: formulario } \\
\text { con preguntas } \\
\text { abiertas. }\end{array}$ & TA & $\begin{array}{l}\text { Cuestionario para conocer los } \\
\text { modelos de los alumnos sobre } \\
\text { periodismo político y Europa } \\
\text { tras cursar el CIMA. }\end{array}$ & $\begin{array}{c}30 \\
\text { minutos }\end{array}$ \\
\hline
\end{tabular}

\section{Cuestionario de evaluación}

Como instrumento de evaluación se ha diseñado un cuestionario inicial-final (Rivero y Porlán, 2017), que permite analizar los modelos mentales de los estudiantes y hacer un seguimiento de la evolución de su aprendizaje al finalizar una unidad didáctica. El cuestionario se vincula con los problemas y contenidos claves del CIMA, que en mi caso versan sobre la información política en asuntos europeos. Las preguntas se acompañaron de un preámbulo, en el que se subrayaba el funcionamiento a través de pequeñas redacciones de alumnos.

El cuestionario expone los tres grandes problemas del CIMA, organizados en forma de preguntas concretas:

Ciclos de Mejora en el Aula (2020). Experiencias de Innovación Docente de la US Esta obra se distribuye con la licencia Creative Commons 
- Problema 1 (especialización de impacto). 1) ¿A quién y dónde acudirías para construir una noticia veraz sobre la Unión Europea? Justifica tu decisión. 2) ¿Cómo valorarías la información política comunitaria de tus competidores en términos cuantitativos y cualitativos? 3) ¿De qué manera crees que los ciudadanos se informaron de las últimas elecciones europeas?

- Problema 2 (implicaciones democráticas). 4) ¿Consideras que el tipo de periodismo practicado con Europa tiene implicaciones en el día a día? Argumenta tu valoración. 5) ¿Por qué debería contribuir tu medio de comunicación a tomar decisiones democráticas fundamentadas en lo referente a la UE?

- Problema 3 (fórmulas de innovación). 6) ¿Se te ocurren maneras de hacer más atractiva ese tipo de información política? 7) ¿Cuál sería la primera medida que tomarías si fueras el jefe de redacción responsable del área? ¿Por qué esa y no otra?

\section{Aplicación del CIMA}

\section{Relato resumido de las sesiones}

Semana 1 (miércoles 11 y jueves 12 noviembre de 2020) El CIMA se estructuró en cuatro sesiones, de dos horas cada una. La semana anterior al comienzo de su realización los estudiantes pudieron responder de manera anónima (usando un identificador) y voluntaria al cuestionario inicial con preguntas abiertas. De 75 alumnos matriculados, 41 participaron en este ejercicio y, por tanto, fueron objeto de un seguimiento en la evolución de sus modelos mentales. El cuestionario se trató en horario de clase, aunque online debido a las restricciones sanitarias. Esta tarea me permitió obtener una panorámica de los modelos mentales, identificando posibles lugares comunes sobre los que guiar el aprendizaje.

Ciclos de Mejora en el Aula (2020). Experiencias de Innovación Docente de la US Esta obra se distribuye con la licencia Creative Commons 
La primera clase comenzó con la introducción a la dinámica participativa basada en casos que íbamos a aplicar durante esas dos semanas. Ya habíamos realizado un pequeño CIMA el mes anterior, así que les comenté que ahora seguiríamos una dinámica parecida, centrada en este caso en la acción periodística en estudios europeos. Incidí en que durante esas dos semanas funcionarían como una redacción televisiva que se enfrenta a decisiones éticas de calado para comunicar la UE. También aproveché para aludir a que habría un ejercicio voluntario para la nota, empleando una motivación extrínseca (Rivero y Porlán, 2017). La gran pregunta estructurante que les formulé era ¿A quién llamó para hablar con Europa?

Concluida esta pequeña introducción, en la que busqué que tomaran conciencia de la enorme responsabilidad que posee una redacción periodística en la construcción de la imagen de Europa o de la ausencia de ella, pasé a plantearles el primer caso práctico. Proyecté dos portadas de periódicos que recogían la noticia de los fondos de la UE contra el Covid-19, junto con una serie de preguntas a las que debían responder primero individualmente y luego en grupos de 5 alumnos, a través de Blackboard Collaborate. Esos documentos visuales exponían un potencial problema deontológico, en cuanto podían suponer una apropiación nacional de la política comunitaria con fines utilitaristas. Esto obligaba a los alumnos a reflexionar sobre la capacidad que como periodistas ostentan de orientar la visión de la opinión pública acerca del tema.

Transcurridos 15 minutos, en los que tuvieron que poner por escrito las reflexiones que efectuaban, les invité a contárselas al conjunto de los compañeros. La respuesta fue relativamente positiva, puesto que la mayor parte de los grupos se animó a debatir durante 15-20 minutos. No obstante, hubo tres que no lo hicieron por distintos problemas técnicos. Más allá de esta circunstancia, el debate 
resultó interesante, generándose posiciones enfrentadas entre aquellos que observaban un dilema ético en las portadas y los que no. Las opiniones estuvieron más repartidas de que lo había imaginado, confrontando las ideas de los estudiantes con la teoría de la lejanía de los asuntos comunitarios. Reduje esta fase de aportación teórica a 20 minutos porque el tiempo de debate se alargó algo más de lo previsto.

Tras ello se proyectaron dos noticias sobre el cambio de hora y la Comisión Europea (TVE y A3), que conectan con la falta de politización en torno a la UE. Se formularon tres cuestiones para la discusión en grupo, compartiendo sus ideas sobre el problema. Dejé un cuarto de hora de debate para las preguntas sugeridas. La discusión posterior resultó positiva, con más información propia por parte de los estudiantes, lo que seguramente denota una mayor opinión personal acerca del tema. Sus críticas a aspectos televisivos como el infoentrenimiento, del que pusieron ejemplos curiosos como los programas matinales de las grandes cadenas, me sirvieron para confrontarlas con las características de la información europea.

Me valí de ese potencial clima para presentar el último caso práctico de la semana, que versaba sobre dos portadas periodísticas en las que se destacaban elementos anecdóticos de las elecciones al Parlamento Europeo. A pesar de un vídeo introductorio y del material abordado el día anterior, el debate posterior al análisis fue menor, evidenciándose cierto desconocimiento de base y una gran brecha entre distintos alumnos. Este hecho fundamentó que me explayara 10 minutos más de las previstos en la confrontación teórica de las diferencias entre las instituciones europeas. La semana finalizó con un apartado de síntesis en el que la participación sí aumentó, canalizada a través de respuestas a preguntas de resumen. Asimismo, les planteé el visionado de un reportaje en casa, a partir del cual continuaríamos la siguiente ronda del CIMA.

Ciclos de Mejora en el Aula (2020). Experiencias de Innovación Docente de la US Esta obra se distribuye con la licencia Creative Commons 
Semana 2 (miércoles 18 y jueves 19 de noviembre de 2020)

La segunda semana se inició con la realización de una encuesta corta online por parte de los estudiantes a través de Wooclap. Con ello pretendía conocer las ideas que traían de la semana anterior. Me resultó sorprendente que nunca hubieran utilizado esa aplicación y solo una vez Kahoot a lo largo de la carrera, según comentaron, lo que puede explicar su gran interés reflejado en numerosas intervenciones en el chat de Blackboard Collaborate. De hecho, al finalizar la clase, 9 alumnos me escribieron para agradecer el desarrollo de esa actividad, en la que las preguntas se articularon con dimensión profesional. Dos ejemplos de lo anterior son a dónde acudirías para obtener información de una determinada personalidad europea o por qué tomarías una decisión en concreto para contextualizar una información. La encuesta reveló un notable grado de conocimiento de las operaciones conceptuales trabajadas previamente. Las principales deficiencias aparecieron en la diferenciación periodística entre TJUE (Tribunal de Justicia de la Unión Europea) y TEDH (Tribunal Europeo de Derecho Humanos), una cuestión ya descrita como conflictiva en el diseño del CIMA.

Siguiendo este problema del mapa de contenidos, se emprendió un trabajo práctico de análisis grupal de un texto periodístico, en el que se podía observar una buena acción en la explicación de esos dos entes jurídicos. La fase analítica se extendió durante 40 minutos, dado que en sesiones previas había observado que requerían de un tiempo prolongado para estas actividades. Para la discusión les formulé una serie de preguntas encadenadas: ¿Cómo accederías a fuentes europeas? ¿Por qué esas y no otras? ¿Cuáles podrían ser las implicaciones de esa decisión? Estas cuestiones funcionaron bien; prácticamente participaron todos los grupos y de forma más extensa, ofreciendo además dudas relativas a cómo ser lo

Ciclos de Mejora en el Aula (2020). Experiencias de Innovación Docente de la US Esta obra se distribuye con la licencia Creative Commons 
más divulgativo posible en el tratamiento de esas instituciones. Esto disminuyó sensiblemente la siguiente fase de confrontación teórica con fórmulas originales de comunicar esos asuntos.

Una vez terminada la aportación de tendencias originales detectadas en la práctica profesional, pasé a reproducirles un programa radiofónico ilustrativo de cómo unir los intereses locales con los europeos mediante una atractiva propuesta sonora. Dedicamos 10 minutos a su escucha activa, compartiendo impresiones acerca de sus puntos fuertes y débiles. Basándome en ese audio y en el visionado de un clip introductorio al podcast, se propuso la elaboración de una propuesta al respecto, para la que los estudiantes debían brindar un guion lo más detallado posible. Destinamos 35 minutos y les pedí que guardaran sus propuestas, porque serían parte de la tarea voluntaria final. Concluido el tiempo para el podcast, la última actividad consistió en que redactaran de manera individual un informe deontológico sobre las implicaciones éticas que poseía todo lo visto durante esas cuatro sesiones en su futuro profesional, dejándoles media hora para esta reflexión. No hubo apenas dudas, probablemente debido a que tenían reciente un informe ético que llevaron a cabo para un pequeño CIMA previo.

Como punto final, recordé los tres grandes problemas afrontados y las respuestas secuenciales que les habíamos ido otorgando de forma conjunta en clase. Establecí una serie de preguntas, que permitieron que esta etapa estuviera estructurada, con varias aportaciones de los estudiantes en casa. Se compartió ya un espacio online para que subieran el guion de podcast grupal y su informe individual. Además, solicité a los 41 alumnos que habían completado el cuestionario inicial que lo realizaran de nuevo

Ciclos de Mejora en el Aula (2020). Experiencias de Innovación Docente de la US Esta obra se distribuye con la licencia Creative Commons 
como sistema para conocer anónimamente la evolución del aprendizaje. Supuso una pena no poder ver las caras de los estudiantes y apreciar su grado de interés con el CIMA, pero una buena parte de la clase participó y acabó generando propuestas de podcast e informes deontológicos de un cierto grado de sofisticación.

\section{Evaluación del aprendizaje de los estudiantes}

El aprendizaje de los estudiantes se ha evaluado mediante un cuestionario individual, dotado de 7 preguntas abiertas ya citadas. 41 alumnos respondieron a los cuestionarios inicial y final, realizados a través de la herramienta de formularios de Google sobre la información política en asuntos europeos. Se seleccionaron 15 al azar para el análisis de la evolución de su aprendizaje en forma de escalera, que representa de manera gráfica y con porcentajes los distintos niveles alcanzados en cada una de las preguntas, reflejando igualmente los obstáculos entre niveles. Para esta publicación se escogen dos escaleras de preguntas ( 1 y 7 ) en las que se han producido divergencias en el progreso de aprendizaje. El color rojo se refiere al porcentaje de estudiantes en el cuestionario inicial, mientras que el verde lo hace a los datos finales.

D. Servicios especializados UE. $0 \% / / 33 \%$

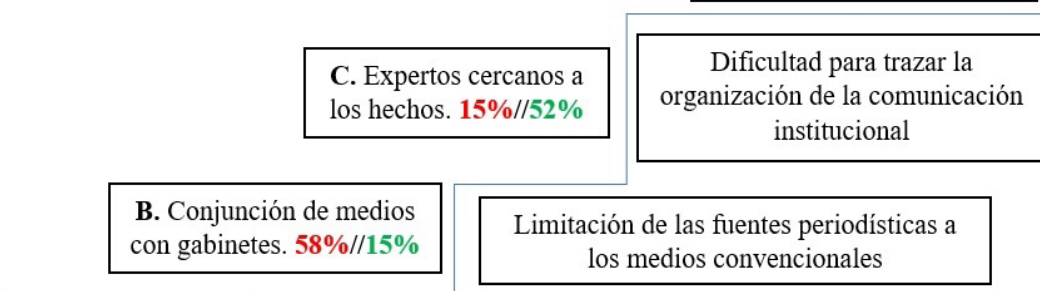

A. Medios como fuentes. $27 \% / / 0 \%$

Figura 3. Escalera para la pregunta 1, relativa al uso de fuentes veraces para noticias sobre la UE

Ciclos de Mejora en el Aula (2020). Experiencias de Innovación Docente de la US Esta obra se distribuye con la licencia Creative Commons 
C. Concienciar mediante información de interés y atractiva. $27 \% / / 38 \%$
D. Conocer las necesidades de la audiencia y promover noticias asequibles que redunden en su participación. 10\%//20\%

Limitación de la actividad periodística a los medios, olvidando el punto de partida de la audiencia
B. Asegurar la máxima obietividad. $22 \% / / 14 \%$
Excesiva dependencia de enfoques cuantitativos relativos a la objetividad
A. Aumentar la cobertura mediática. $41 \% / / 28 \%$
Figura 4. Escalera para la pregunta 7, referente a la priorización de medidas en una redacción

La escalera de la figura 3 muestra un notable avance, puesto que ningún alumno permanece en el peldaño inferior y la inmensa mayoría se sitúa en los niveles más elevados. Los obstáculos, referentes a integrar la comunicación institucional en sus modelos mentales sobre fuentes, fueron superados, probablemente porque las actividades de contraste evidenciaron que sin esa información es fácil caer en contradicciones cuando se elaboran noticias de la UE. En cambio, el efecto del CIMA para la pregunta 7 del cuestionario ha sido mucho menor, con un $42 \%$ de los estudiantes en los escalafones más bajos. El mito de la objetividad periodística ha revelado aquí su fuerza como barrera, lo que demanda poner en marcha actividades de interacción con la audiencia, en las que podrían percatarse de sus necesidades noticiosas.

Con el fin de evaluar el avance de cada estudiante se diseña un cuadro de progresión, de cual se ofrecen $10 \mathrm{ca-}$ sos como ejemplo en este apartado. Por cada salto de escalón en la escalera de aprendizaje se concede 0.5 puntos. Cuando dicho paso conlleva un peldaño considerado más exigente $y$, por tanto, más alto en la figura, se atribuye 1 punto. La escala comprende de la categoría A (mínima) a D (máxima).

Ciclos de Mejora en el Aula (2020). Experiencias de Innovación Docente de la US Esta obra se distribuye con la licencia Creative Commons 
Tabla 3. Cuadro de progresión individual

\begin{tabular}{|c|c|c|c|c|c|c|c|c|c|c|c|c|c|c|c|}
\hline \multicolumn{16}{|c|}{ Preguntas } \\
\hline Estudiante & 11 & 1F & 21 & $2 F$ & 31 & $3 F$ & 41 & $4 F$ & 51 & $5 \mathbf{F}$ & 6I & $6 F$ & 71 & $7 F$ & Puntuación \\
\hline \multirow{2}{*}{1} & B & C & A & A & B & B & C & C & B & D & B & C & A & B & \multirow{2}{*}{+3} \\
\hline & \multicolumn{2}{|c|}{+0.5} & \multicolumn{2}{|c|}{0} & & & \multicolumn{2}{|c|}{0} & \multicolumn{2}{|c|}{+1.5} & & & \multicolumn{2}{|c|}{+0.5} & \\
\hline \multirow{2}{*}{2} & A & C & A & B & B & c & A & C & B & D & B & C & B & C & \multirow{2}{*}{+6} \\
\hline & \multicolumn{2}{|c|}{+1} & \multicolumn{2}{|c|}{+1} & \multicolumn{2}{|c|}{+0.5} & \multicolumn{2}{|c|}{+1} & \multicolumn{2}{|c|}{+1.5} & \multicolumn{2}{|c|}{+0.5} & \multicolumn{2}{|c|}{+0.5} & \\
\hline \multirow{2}{*}{3} & B & B & A & B & B & C & C & C & B & C & B & C & A & A & \multirow{2}{*}{+2.5} \\
\hline & \multicolumn{2}{|c|}{0} & \multicolumn{2}{|c|}{+1} & \multicolumn{2}{|c|}{+0.5} & \multicolumn{2}{|c|}{0} & \multicolumn{2}{|c|}{+0.5} & \multicolumn{2}{|c|}{+0.5} & \multicolumn{2}{|c|}{0} & \\
\hline \multirow{2}{*}{4} & B & D & B & C & C & D & B & B & C & D & C & D & C & D & \multirow{2}{*}{+6} \\
\hline & \multicolumn{2}{|c|}{+1.5} & \multicolumn{2}{|c|}{+0.5} & & & c & & & & & & + & & \\
\hline & A & C & A & D & A & C & B & C & A & D & A & C & A & A & \\
\hline 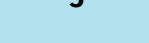 & & & & & & & +0 & & & & & & 0 & & 7 \\
\hline & C & D & B & D & D & D & D & D & C & D & C & D & C & C & \\
\hline 6 & & & & & & & c & & & & & & 0 & & +4.5 \\
\hline & B & D & C & B & B & C & C & D & C & D & B & C & C & D & \\
\hline 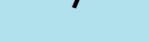 & & & & & & .5 & + & & & & & & + & & TJ \\
\hline & A & C & A & A & B & C & B & C & A & B & B & C & B & C & \\
\hline 0 & & & & & & .5 & +0 & & & & & & +0 & & +4 \\
\hline & A & C & A & B & A & C & B & B & A & D & A & C & B & D & \\
\hline 8 & & & & & & 1 & c & & & & & & +1 & & +.5 \\
\hline & B & D & C & c & C & D & B & C & B & C & C & C & C & C & \\
\hline 10 & & & & & & 1 & +0 & & $+c$ & & & & 0 & & T.J.J \\
\hline
\end{tabular}

Las preguntas del cuestionario en las que se evidencia un mayor progreso en los modelos de los estudiantes son la 1 (fuentes para la construcción de noticias veraces en torno a la UE) y la 5 (contribución democrática de la especialización). En cambio, las cuestiones 3 (modos de información) y 7 (priorización de medidas) reflejan el menor grado de avance en la escala establecida. Esto puede encontrarse motivado por la ausencia de actividades de interacción con la audiencia, gracias a las cuales se accede a un mayor conocimiento de la ciudadanía. En futuros CIMA, apuesto por implementar acciones a pie de calle para esas

Ciclos de Mejora en el Aula (2020). Experiencias de Innovación Docente de la US Esta obra se distribuye con la licencia Creative Commons 
preguntas, como pequeñas encuestas en barrios de distintas clases sociales. También se aprecian diferencias significativas en el aprovechamiento de los estudiantes. Un tercio de los mismos ha obtenido una puntuación igual o inferior a 4 puntos en la suma de saltos de aprendizaje, mientras que el resto de la muestra (10 de 15 estudiantes) sí experimenta una mejora destacable.

\section{Evaluación del CIMA}

El principal cambio conseguido es que los alumnos adquirieran conciencia de su responsabilidad como periodistas en el plano de la información política europea, verbalizando y poniendo por escrito sus conclusiones. Un total de 40 estudiantes formularon propuestas de podcast, aplicando profesionalmente los contenidos del CIMA. La atención pareció evolucionar de menos a más, de ahí que la dimensión dinámica de la segunda semana pudiera contribuir a incrementar la motivación. Este proceso se antojó tanto grupal como individual, con actividades de ambas categorías. Los estudiantes hicieron suyas algunas de las preocupaciones de la profesión, empleando términos académicos (apropiación nacional, despolitización, etc.).

Los debates en clase siempre se saldaron con disparidad de opiniones, una muestra de que la materia con la que trabajaron no es blanca o negra, sino que admite muchos matices. Lo que más me importa como docente es que se conciencien y dediquen tiempo a reflexionar antes de tomar una decisión de esas características como periodistas. Creo que resultó un acierto definir un marco en el que actuaron como la redacción de un medio de comunicación, un sentido profesionalizante en el que han incidido otros ciclos de mejora (Baena-Sánchez, 2019; Romero-Domínguez, 2019). El inconveniente este año radicó en el escenario de no presencialidad.

Ciclos de Mejora en el Aula (2020). Experiencias de Innovación Docente de la US Esta obra se distribuye con la licencia Creative Commons 
Como dificultades adicionales en el desarrollo del CIMA, esa situación de enseñanza en remoto impidió realizar un seguimiento más personalizado y tangible del aprendizaje de cada grupo. Con el objetivo de mantener el interés varié el tipo de medios de comunicación en las actividades, abarcando portadas de prensa, noticias de televisión y piezas sonoras como el podcast. El momento en el que percibí una menor participación fue al final de la primera semana, quizás por la dificultad de conservar un nivel de atención elevado durante tiempos prolongados. El inicio de la siguiente sesión con una encuesta de Wooclap pretendía precisamente enganchar de nuevo al alumnado, algo que se consiguió en cierta manera según la participación en la discusión posterior. Otro elemento a tener en cuenta es la necesidad de reajustar los tiempos. No se produjeron grandes desfases en la planificación, pero sí que el debate sobre ciertos temas se extendiera algunas veces más y otras menos de lo contemplado.

Los aspectos de la experiencia que pretendo incorporar a la práctica docente habitual son diversos. Mi objetivo es conocer el aprendizaje final alcanzado en futuras unidades didácticas, así que resulta muy pertinente efectuar la comparación de los cuestionarios inicial y final a través de las escaleras de aprendizaje (Rivero y Porlán, 2017). En mi breve experiencia docente había utilizado rúbricas para categorizar las respuestas de los estudiantes y asignar una calificación, pero el modelo de escalera se halla mucho más conectado con la realidad de los alumnos, al derivarse de su experiencia. Esto conlleva una reinterpretación de la evaluación hacia parámetros más dinámicos y continuos, dirigidos también a la docencia.

Como principios didácticos que han guiado la experimentación del CIMA y que deben permanecer en esta nueva relación profesor-alumno, selecciono los siguientes:

- La problematización de los contenidos a través de mapas (García-Díaz, Porlán y Navarro, 2017), integrando conceptos, procedimientos y actitudes que se vinculen

Ciclos de Mejora en el Aula (2020). Experiencias de Innovación Docente de la US Esta obra se distribuye con la licencia Creative Commons 
con los problemas de la profesión. Las preguntas encadenadas articularán la presentación de estos contenidos (Finkel, 2008), mediante una secuencia de actividades en coherencia con el modelo metodológico posible (De-Alba y Porlán, 2017).

- En cuanto a esta metodología, las clases han de comenzar con los intereses de los estudiantes, brindando experiencias de aprendizaje diversas (Bain, 2007). Se busca también llegar siempre a un punto de desenlace (Finkel, 2008), siguiendo un esquema guionizado que incluya tareas fuera del aula para fomentar el aprendizaje autónomo (Bain, 2007).

- En relación con la evaluación, se apuesta por conocer el aprendizaje al final de la secuencia didáctica (Finkel, 2008) y emplear un modelo centrado en sus necesidades como futuros periodistas (Clark y Jones, 2017). Se analiza la evolución del conocimiento, comparando los modelos iniciales y finales de los estudiantes mediante tareas como los informes de trabajo (Rivero y Porlán, 2017). El rol activo del alumnado funciona como principio didáctico.

- Por último, se estima que la evaluación afecta también al ejercicio docente, con herramientas para su medición como el diario del profesor y las encuestas de opinión (Rivero y Porlán, 2017), que trascienden de las aportaciones informales de estudiantes. Esta retroalimentación posibilita la adopción de decisiones fundamentadas en el aula.

Palabras clave: Periodismo Político y Económico, Grado en Periodismo, Docencia Universitaria, Experimentación Docente Universitaria, Información Europea.

Keywords: Political and Economic Journalism, Journalism Degree, University Teaching, University Teaching Innovation, EU Journalism.

Ciclos de Mejora en el Aula (2020). Experiencias de Innovación Docente de la US Esta obra se distribuye con la licencia Creative Commons 


\section{Referencias bibliográficas}

Baena-Sánchez, F. (2019). Una propuesta de aprendizaje basada en el periodismo-acción en el aula. En Porlan R. y Navarro, E. (Coord.), Ciclos de mejora en el aula, año 2019: experiencias de innovación docente de la Universidad de Sevilla (pp. 1705-1730). Sevilla: Editorial Universidad de Sevilla.

Bain, K. (2007). Lo que hacen los mejores profesores universitarios. Valencia: Publicacions Universitat de València.

Clark, T. y Jones, A. (2017). Not what they want, but what they need: Teaching politics to journalism students. Teaching Public Administration, 35 (2), 223-234.

De-Alba, N. y Porlán, R. (2017). La metodología de enseñanza. En Porlán, R. (Coord.), Enseñanza universitaria. Cómo mejorarla (pp. 37-53). Madrid: Ediciones Morata

Fajardo-Trigueros, C. y Rivas-de-Roca, R. (2020). La acción de la UE en España ante la "infodemia" de desinformación por el COVID-19. Revista de Estilos de Aprendizaje, 13 (26), 19-32.

Finkel, D. (2008). Dar clase con la boca cerrada. Valencia: Universitat de València.

García-Díaz, E., Porlán, R. y Navarro, E. (2017). Los fines y los contenidos de enseñanza. En Porlän, R. (Coord.), Enseñanza universitaria. Cómo mejorarla (pp. 55-72). Madrid: Ediciones Morata.

Porlán, R. (Coord.). (2017). Enseñanza universitaria. Cómo mejorarla. Madrid: Ediciones Morata.

Rivero, A. y Porlán, R. (2017). La evaluación en la enseñanza universitaria. En Porlán, R. (Coord.), Enseñanza universitaria. Cómo mejorarla (pp. 74-91). Madrid: Ediciones Morata.

Romero-Domínguez, L. (2019). Ciclo de mejora en el aula para la asignatura de Técnicas de Investigación en el Periodismo. En Porlán R. y Navarro, E. (Coord.), Ciclos de mejora en el aula, año 2019: experiencias de innovación docente de la Universidad de Sevilla (pp. 933-954). Sevilla: Editorial Universidad de Sevilla.

Ciclos de Mejora en el Aula (2020). Experiencias de Innovación Docente de la US Esta obra se distribuye con la licencia Creative Commons 